2

3 Impacts of aerosol-photolysis interaction and aerosol-radiation

4 feedback on surface-layer ozone in North China during a

5 multi-pollutant air pollution episode

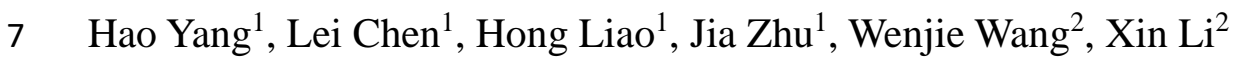

$9{ }^{1}$ Jiangsu Key Laboratory of Atmospheric Environment Monitoring and Pollution 10 Control, Jiangsu Collaborative Innovation Center of Atmospheric Environment and Equipment Technology, School of Environmental Science and Engineering, Nanjing

12 University of Information Science \& Technology, Nanjing 210044, China

$13{ }^{2}$ State Joint Key Laboratory of Environmental Simulation and Pollution Control, 14 College of Environmental Sciences and Engineering, Peking University, Beijing 15 100871, China

17 Correspondence: Lei Chen (chenlei@nuist.edu.cn) and Hong Liao 18 (hongliao@nuist.edu.cn) 
1 Table S1. Locations of the three stations from NOAA's National Climatic Data Center 2 used in this study.

\begin{tabular}{ccc}
\hline Station & Latitude $\left(^{\circ}\right)$ & Longitude $\left(^{\circ}\right)$ \\
\hline Beijing & 40.08 & 116.585 \\
Tianjin & 39.1 & 117.167 \\
Baoding & 38.733 & 115.483 \\
\hline
\end{tabular}

3

4 
1 Table S2. Locations of the thirty-two stations from China National Environmental

2 Monitoring Center used in this study.

\begin{tabular}{|c|c|c|}
\hline Station & Latitude $\left(^{\circ}\right)$ & Longitude $\left({ }^{\circ}\right)$ \\
\hline Beijing_1 & 39.8673 & 116.366 \\
\hline Beijing_2 & 40.2865 & 116.17 \\
\hline Beijing_3 & 39.9522 & 116.434 \\
\hline Beijing_4 & 39.8745 & 116.434 \\
\hline Beijing_5 & 39.9716 & 116.473 \\
\hline Beijing_6 & 39.9425 & 116.361 \\
\hline Beijing_7 & 39.9934 & 116.315 \\
\hline Beijing_8 & 40.1438 & 116.72 \\
\hline Beijing_9 & 40.3937 & 116.644 \\
\hline Beijing_10 & 40.1952 & 116.23 \\
\hline Beijing_11 & 40.0031 & 116.407 \\
\hline Beijing_12 & 39.9279 & 116.225 \\
\hline Tianjin_1 & 39.097 & 117.151 \\
\hline Tianjin_2 & 39.173 & 117.193 \\
\hline Tianjin_3 & 39.1654 & 117.145 \\
\hline Tianjin_4 & 39.1205 & 117.184 \\
\hline Tianjin_5 & 39.1082 & 117.237 \\
\hline Tianjin_6 & 39.0927 & 117.202 \\
\hline Tianjin_7 & 39.2133 & 117.1837 \\
\hline Tianjin_8 & 39.1337 & 117.269 \\
\hline Tianjin_9 & 39.0877 & 117.307 \\
\hline Tianjin_10 & 39.0343 & 117.707 \\
\hline Tianjin_11 & 38.8394 & 117.457 \\
\hline Tianjin_12 & 39.124 & 117.401 \\
\hline Tianjin_13 & 39.1587 & 117.764 \\
\hline Tianjin_14 & 38.9194 & 117.157 \\
\hline Baoding_1 & 38.8632 & 115.493 \\
\hline Baoding_2 & 38.8957 & 115.5223 \\
\hline Baoding_3 & 38.9108 & 115.4713 \\
\hline Baoding_4 & 38.8416 & 115.4612 \\
\hline Baoding_5 & 38.8756 & 115.442 \\
\hline Baoding_6 & 38.8707 & 115.5214 \\
\hline
\end{tabular}



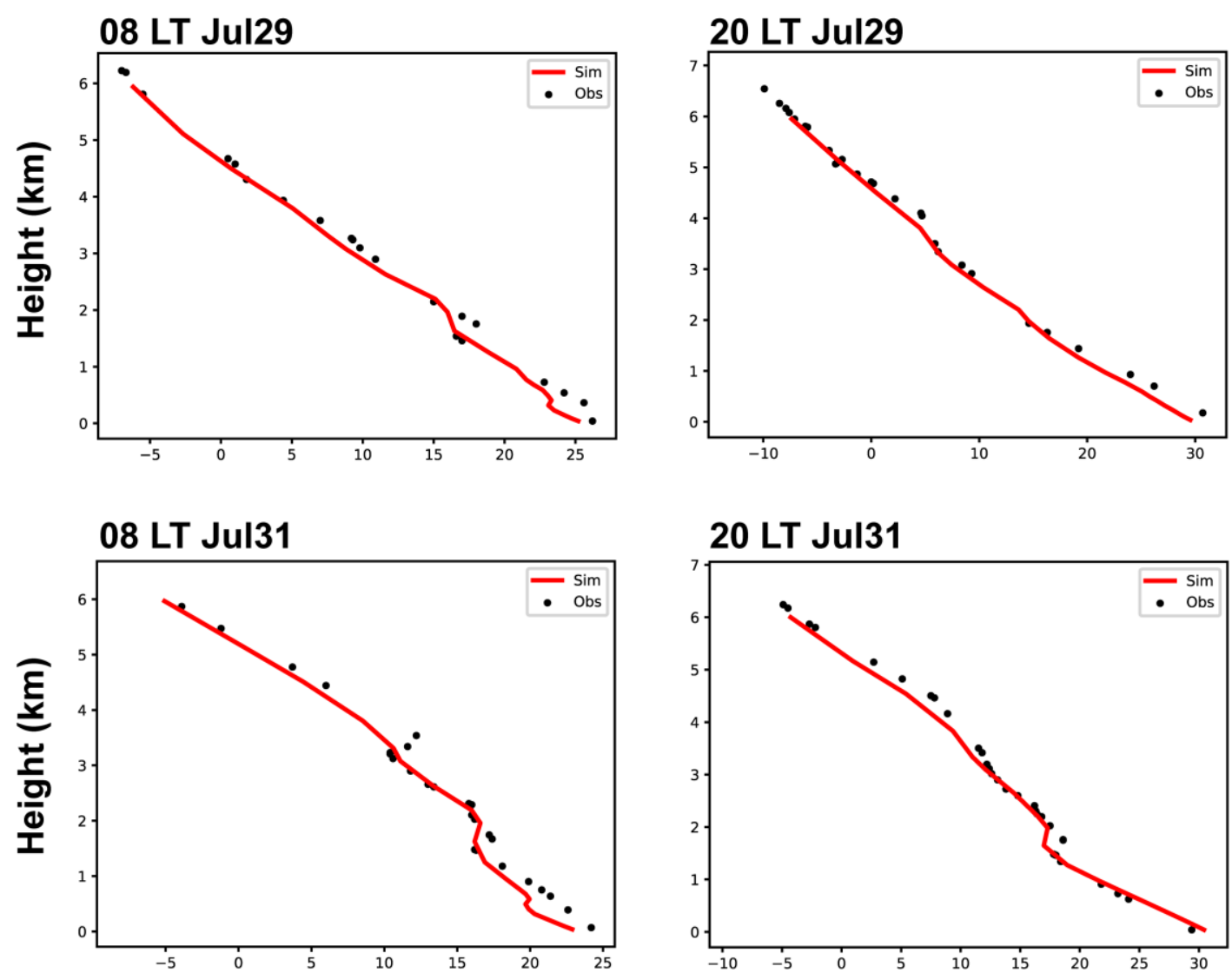

\section{LT Aug01}
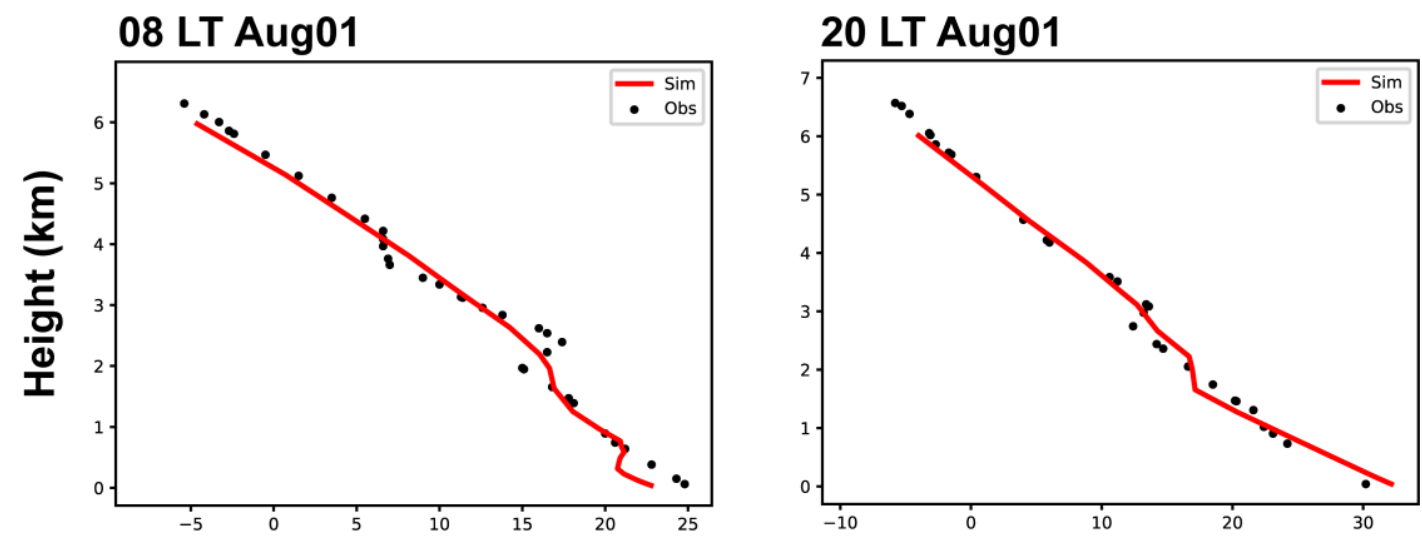

2 Figure S1. Observed (black dots) and simulated (red lines) temperature profiles in

3 Beijing $\left(39.93^{\circ} \mathrm{N}, 116.28^{\circ} \mathrm{E}\right)$ at 08:00 and 20:00 LST on $29 \mathrm{July,} 31 \mathrm{July}$, and 1 4 August 2014. 

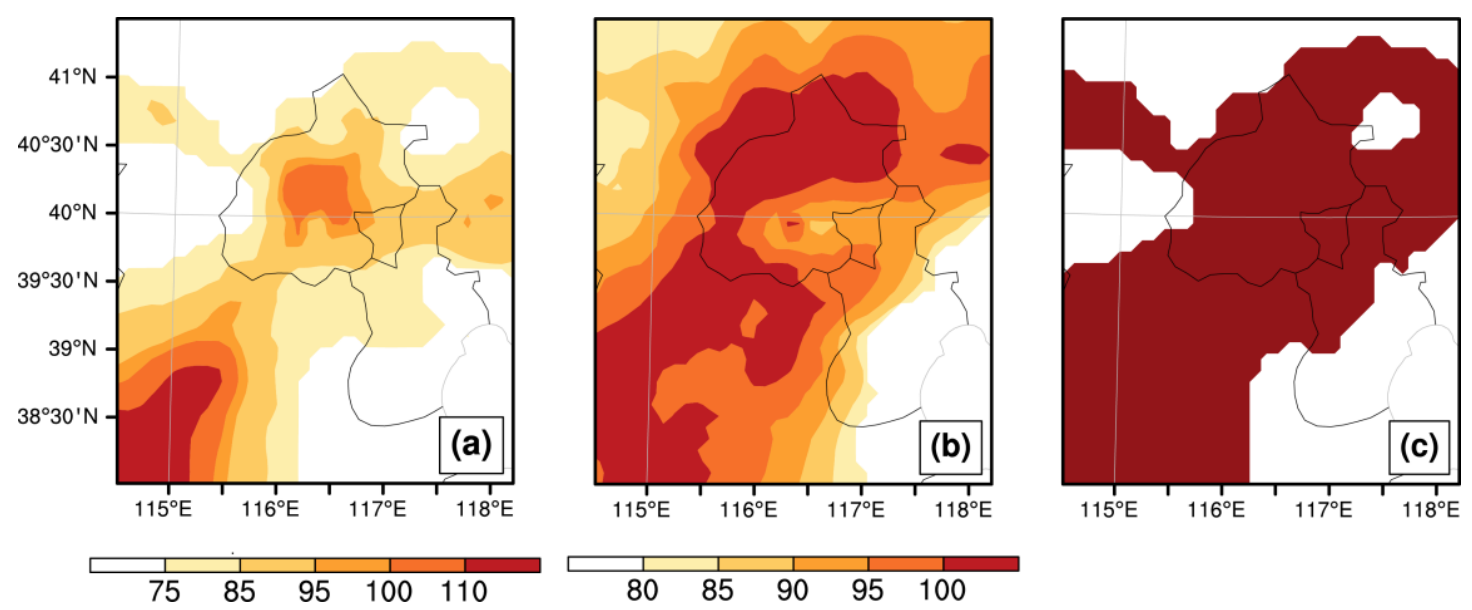

2 Figure S2. The spatial distributions of simulated (a) $\mathrm{PM}_{2.5}\left(\mu \mathrm{g} \mathrm{m} \mathrm{m}^{-3}\right)$ and (b) MDA8

$3 \mathrm{O}_{3}(\mathrm{ppb})$ concentrations averaged during 28 July to 3 August 2014. (c) The defined 4 complex air pollution areas (CAPAs, shaded by red) where $\mathrm{PM}_{2.5}$ and MDA8 $\mathrm{O}_{3}$ 5 concentrations are larger than $75 \mu \mathrm{g} \mathrm{m}^{-3}$ and $80 \mathrm{ppb}$, respectively. 

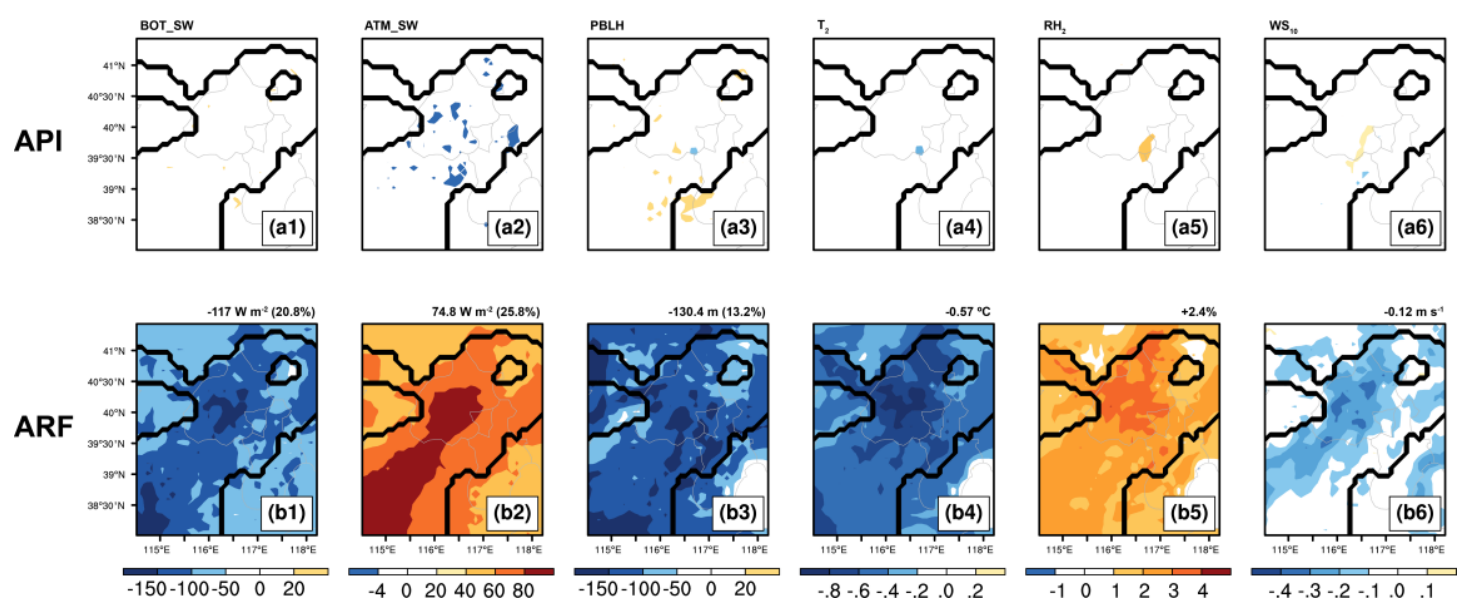

Figure S3. Changes in downward shortwave radiation at the surface (BOT_SW), downward shortwave radiation in the atmosphere (ATM_SW), PBL height (PBLH), 2-m temperature $\left(\mathrm{T}_{2}\right), 2-\mathrm{m}$ relative humidity $\left(\mathrm{RH}_{2}\right)$, and 10 -m wind speed $\left(\mathrm{WS}_{10}\right)$ caused by (a) API and (b) ARF during the daytime (08:00-17:00 LST) from 28 July to 3 August 2014. The calculated changes averaged over CAPAs are also shwon at the 7 top of each panel. 

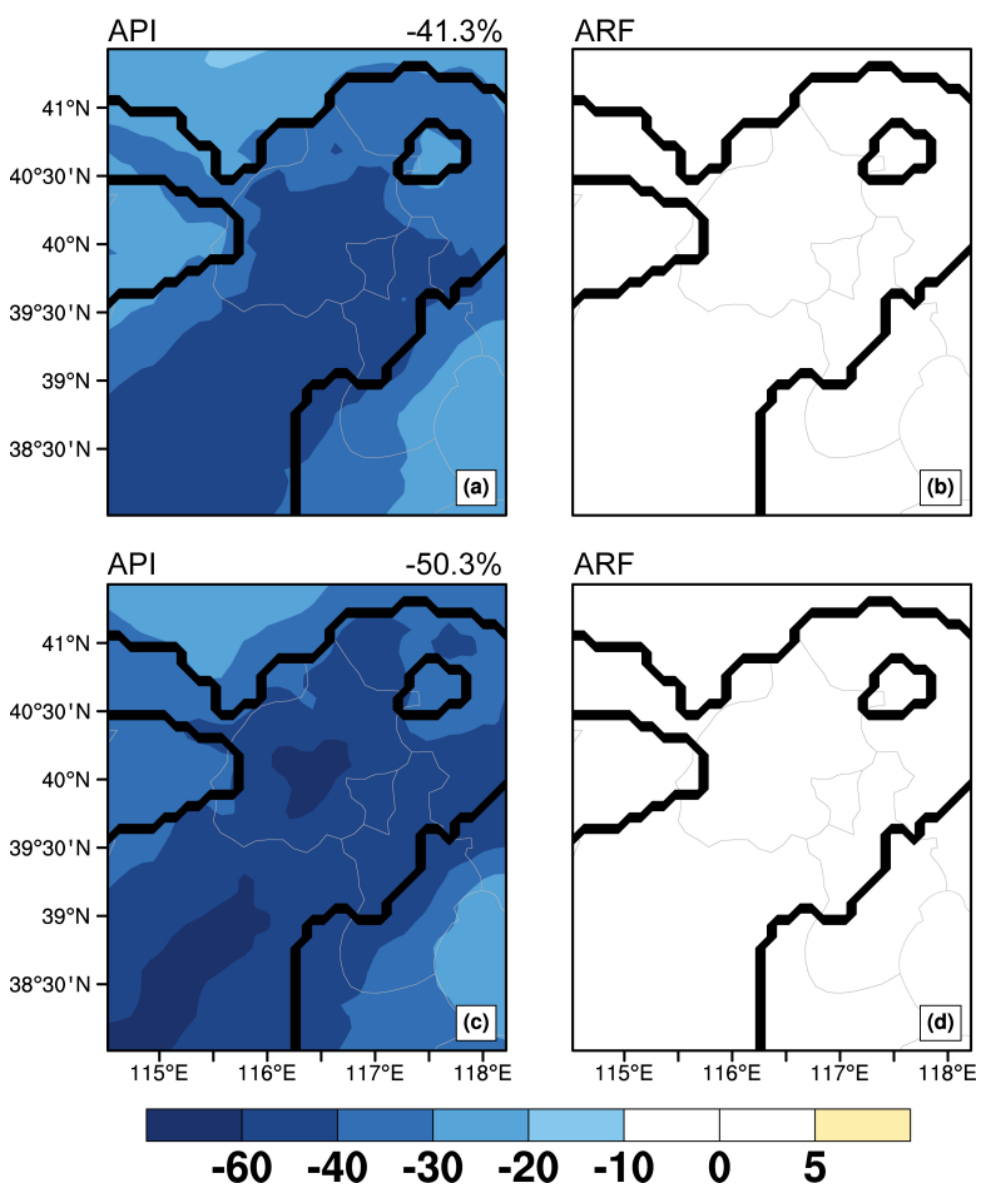

2 Figure S4. Percentage changes in (a-b) $\mathrm{J}\left[\mathrm{NO}_{2}\right]$ and $(\mathrm{c}-\mathrm{d}) \mathrm{J}\left[\mathrm{O}^{1} \mathrm{D}\right]$ caused by API and 3 ARF during the daytime (08:00-17:00 LST) from 28 July to 3 August 2014. The 4 calculated changes averaged over CAPAs are also shwon at the top of each panel. 

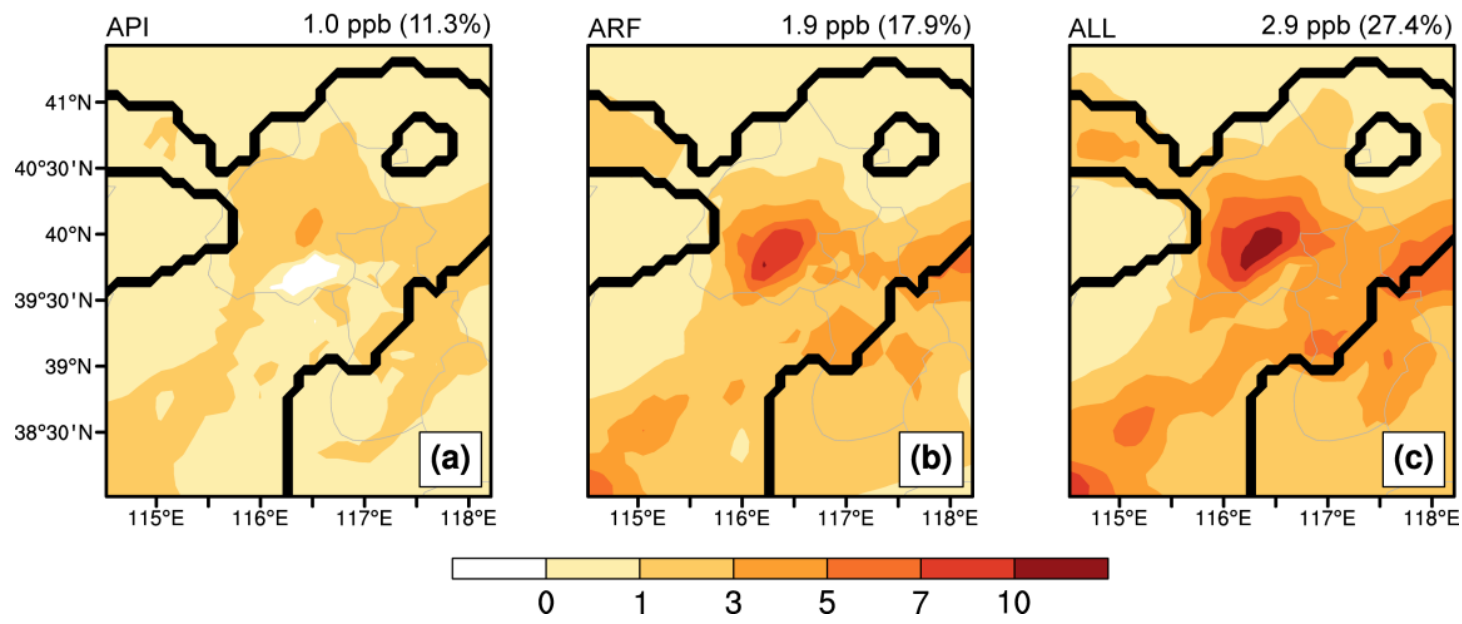

10

2 Figure S5. The changes in simulated surface-layer concentrations of $\mathrm{NO}_{\mathrm{x}}\left(\mathrm{NO}_{2}+\mathrm{NO}\right.$, 3 ppb) caused by (a) API, (b) ARF, and (c) ALL during the daytime (08:00-17:00 LST) 4 from 28 July to 3 August 2014. The calculated changes averaged over CAPAs are also 5 shwon at the top of each panel. 

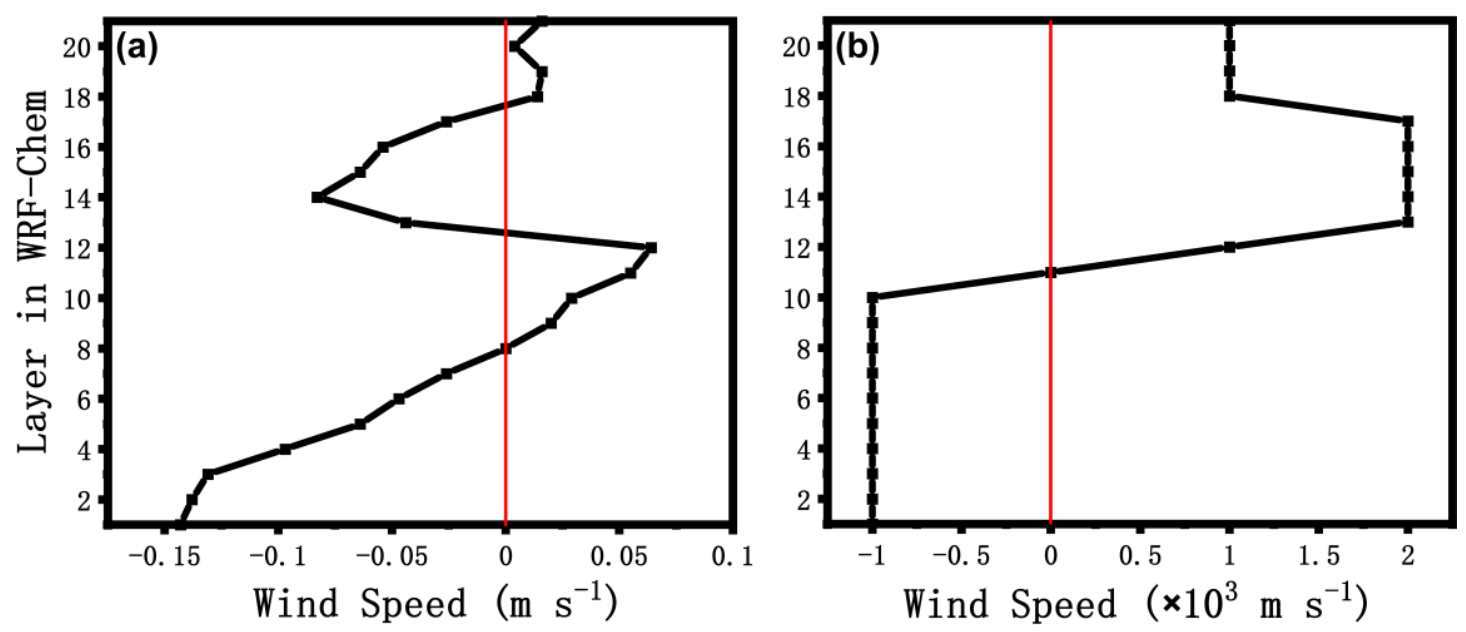

2 Figure S6. The impacts of ARF on (a) horizontal and (b) vertical wind speed in 3 different model layers averaged over CAPAs during the daytime (08:00-17:00 LST) 4 from 28 July to 3 August 2014. 